\title{
$\angle S$ Research Square \\ Age-dependent impact of breast cancer risk perception on mammography screening behavior in Brazilian women
}

\section{Saionara Açucena Vieira Alves}

State University of Paraíba (UEPB)

Mathias Weller ( $\square$ mathiasweller@uepb.edu.br)

Universidade Estadual da Paraiba Mestrado em Saude Coletiva https://orcid.org/0000-0002-5881-4256

Research article

Keywords: Breast cancer; risk perception; mammography

Posted Date: August 18th, 2019

DOl: https://doi.org/10.21203/rs.2.12997/v1

License: @ (i) This work is licensed under a Creative Commons Attribution 4.0 International License. Read Full License 


\section{Abstract}

Background: Previous studies suggest that education and income affect Brazilian women's breast cancer prevention behavior. The present study focused on the impact of perceived risk on mammography screening behavior. Methods: Information regarding socioeconomic variables and risk perception was obtained from 396 healthy women aged 40 - 79 years. Absolute and comparative perceived risk was measured on a seven-point Likert scale. Perceived numeric risk was measured on a percentage scale A Breast Cancer Risk Assessment Tool of five-year and lifetime risk of developing invasive breast cancer was used to estimate real risk. Regression analysis was applied to determine odds ratios (OR) and confidence intervals $(95 \% \mathrm{Cl})$ of independent variables. Results: Women without family history, aged 40 - 49 years and $\geq 50$ years, had a 5.777 (95\%Cl: 2.261- 14.764) and 9.239 (95\% Cl: 4.028-21.194) higher chance, respectively, of having low perceived absolute risk $(p=0.000)$. Regression modelling revealed that women aged between 40 and 49 years with low perceived absolute risk and low educational level, performed regular mammography screening about 2.7 (OR=0.377; 95\%Cl: 0.143-0.989; $p=$ 0.037 and $\mathrm{OR}=0.368 ; 95 \% \mathrm{Cl}: 0.100-1.360 ; \mathrm{p}=0.040$ ) times less often, compared to those ones with high risk perception and high educational level. Education was the only significant variable for women aged $\geq 50$ years ( $p$ = 0.021): Women with low educational level underwent annual and biannual mammography about 3.5 (OR = $0.289 ; 95 \% \mathrm{Cl}: 0.035-2.363)$ and $23.3(\mathrm{OR}=0.043 ; 95 \% \mathrm{Cl}$ : 0.004- 0.420) times less often, respectively, than did women with high education level. Overestimation of numeric and comparative perceived risk, respectively, indicated a negative association with participation in mammography screening $(p=0.021 ; p=0.017)$. Conclusions: Perception of absolute risk depended on family history. The effect of risk perception on mammography screening was age group-dependent, particularly for women aged 40 - 49 years, whereas for women aged $\geq 50$ years, educational level had a more prominent effect. Overestimation of risk was not positively associated with increased adherence on mammography screening.

\section{Background}

Incidence and mortality rates of breast cancer are stable and have even declined in the developed countries of Europe and North America [1]. By contrast, in developing countries in Asia, Africa and South America, mortality rates are increasing [1]. In Brazil, the largest Latin American country, the national cancer institute (INCA) predicted 57,960 new breast cancer cases for 2016 [2]. In southern regions of Brazil, including urban centers like São Paulo and Rio de Janeiro, breast cancer incidence has remained stable or declined in recent years [2,3]. The northeastern region of Brazil, by contrast, has suffered an increase in breast cancer incidence: between 2005 and 2016, the incidence increased from 27.23 to 38.74 new cases per 100,000 women [2,3].

Since 2003, Brazil has a public program for early detection of breast cancer. This is an opportunistic, not an organized screening program, and women are not invited to participate. Furthermore, in Brazil there are conflicting recommendations regarding the age threshold and interval for screening: the ministry of health recommends biannual mammography for women aged 50 to 69 years, whereas the Brazilian Society of Mastology recommends annual mammography screening (MS) starting at 40 years [2,4]. For healthy women aged 70 or older, regular MS is recommended [2,4]. Therefore, for individual women, the recommendations regarding starting age and interval of MS depend mainly on the opinion of their respective physicians.

In Northeast Brazil, women often present at advanced stages of disease (Stage III and IV). High breast cancer mortality rates were attributed to non-adherence to the MS program [5-7]. Brazilian studies identified high income 
as the most important predictor of adherence $[5,8,9]$. Two studies also identified higher educational level as predictor of adherence to the MS program [5,8]. Furthermore, women with first or second- degree relatives who had any type of cancer underwent regular MS more often than did women without any cancer in their families [9].

Perception of risk comprehension may be another variable that affects women's MS behavior. The literature distinguishes between absolute, comparative, and numeric perceived risk [10-12]. Comparative and numeric risk, are generally estimated as the relations between perceived and objective risk. The latter can be measured with various models [13]. Several previous studies focused on breast cancer risk perception of women [11,13-15]. Other studies focused on possible associations between risk perception and women's MS behaviors [10,12,16-20].

To the best of our knowledge, there are no Brazilian studies aimed at elucidation of the possible association between risk perception and women's MS behavior. Increasing incidence and mortality rates in Northeast Brazil highlight the importance of identifying variables that affect adherence to the MS program. We asked whether accurate and overestimated risk perception is associated positively with women's participation on the MS program. Risk perception was analyzed in the context of other important socio-demographic variables.

\section{Methods}

\section{Study population and data collection}

Women were eligible for the study if they were 40 years or older and had not had any type of breast or ovarian cancer. Data sampling was based on interviews of participants by one of the authors. Interviews were performed between March and October 2017. Of each group of related persons, only one woman was interviewed to avoid possible repetitive information from family members. Participating women were directly contacted and interviewed in waiting rooms of the health service center "Dr. Francisco Pinto" and the "Hospital Municipal Dr. Edgley", both in Campina Grande, Northeast Brazil. There were no differences between women at both health service centers. Situated in the interior, about $120 \mathrm{~km}$ west of the state capital João Pessoa on the Atlantic coast, Campina Grande has a population of 385,276 (2010), making it the second largest city in the state of Paraíba [21].

\section{Questionnaire and measures}

Interviews were based on a modified structured questionnaire developed in previous studies. ${ }^{9,22}$ The questionnaire was subdivided into the following sections: 1 . Socioeconomic characteristics; 2 . Reproductive and health characteristics, including information regarding previous biopsies, and breast or ovarian cancer of the participant and first-degree relatives; 3 . Adherence to the MS program; 4. Perception of breast cancer risk.

Educational level was defined as follows: 1. Fundamental school with duration of eight years was defined as "Low"; 2. Middle school with duration of 11 years was defined as "middle". 3. Higher educational levels were defined as "high". Income was defined as minimum wage and multiple values of the minimum. Ethnic origin was based on self-reporting by interviewed women.

Women were asked about their actual adherence to recommendations by the MS program. If asked about mammography utilization, the following options were distinguished: Never, sometimes, every year, and every two years. Perceived absolute and comparative risk were assessed with the questions "How do you classify your risk 
of breast cancer?" and "How do you classify your risk of breast cancer compared to other women of your own age?" Absolute and comparative perceived risk, were measured on a seven-point Likert scale that ranged from "very low to "very high", and from "much lower" to "much higher", respectively. Perceived numeric risk was measured on a percentage scale ranging from 0\% (I have no risk at all for developing breast cancer) to 100\% (I will develop breast cancer either way).

\section{Objective risk and risk perception}

We used the National Cancer Institute's Breast Cancer Risk Assessment Tool (BCRAT; https://www.cancer.gov/bcrisktool/) to calculate participants' five-year and lifetime risk of developing invasive breast cancer. The tool is based on the Gail model [23]. Among the BCRAT risk factors, only information regarding atypical hyperplasia was unavailable. The tool also provides data on mean objective risk at particular ages.

According to a previous study, categories of high and low objective risk were defined as higher versus lower and identical to five-year BCRAT objective risk, than mean objective risk at the same age [10]. Perceived absolute and comparative risk were defined as follows: High perceived risk if women responded "a little high", "high" or "very high" and "a little higher", "higher" or "very much higher", respectively; Low perceived risk if women responded "very low", "low" "a little low" or "intermediate” and "very much lower", "lower”, "a little lower" or "the same”, respectively. Perceived absolute and comparative risk were categorized according to Banegas and colleagues [11] as follows: Accurate, if women with high objective risk had a high perceived risk and if women with low objective risk had a low perceived risk. Underestimate, if women with high objective risk had a low perceived risk. Overestimate, if women with low objective risk had a high, perceived risk.

According to a previous study [11], risk perception was also determined as the difference between perceived numeric risk and five year BCRAT objective risk: BCRAT risk scores were multiplied by 10 to subtract objective risk from perceived numeric risk ( $d$ = Perceived numeric risk- Objective risk). Numeric risk comprehension was defined as follows: Accurate, if $d<10$ and $d>-10$; Underestimate if $d \leq-10$; Overestimate if $d \geq 10$.

\section{Statistical analysis}

Pearson's Chi-Square $\left(\chi^{2}\right)$ test was applied to compare categorized variables. T-test and ANOVA were applied to compare continuous parametric variables. Results of multinomial logistic regression were presented as adjusted odd ratios (OR), 95\% confidence interval $(95 \% \mathrm{Cl})$ and P-value. P values of regression analyses were calculated using likelihood ratio tests (PLRT) for each independent variable. Significant variables of univariate regression analysis were used for regression modeling: Variables with significance level less than 0.2 in the univariate analysis were entered into the model. Then, variables with significance level less than 0.05 were kept in the model. Backward selection was used when significant variables were selected. The final model was tested for fitness using the likelihood ratio test. Statistical analysis was performed using SPSS STATISTICS ${ }^{\text {TM }}$ software (SPPS; IBM company; version 24).

\section{Results}


Mean age ranged from $48.94(S D=12.10)$ years for women who never underwent MS, to $60.95(S D=9.89)$ years for women who underwent MS each second year (Table 1). Of all 108 women who never underwent MS, 75 (69.44\%) were between 40 and 49 years old $(p=0.000$; Table 1). Seventy-three of 108 (67.59\%) who never underwent MS, and 70 of 99 (70.71\%) who sometimes underwent MS, had a low educational level $(p=0.005)$. Of 168 women who underwent MS every year, $41(24.40 \%)$ had a family history ( $p=0.008$; Table1).

During the interviews, women were also asked about limitations and benefits of MS. When women were asked if MS can prevent breast cancer, 357 (90.15\%) responded correctly, that it cannot prevent the disease. Asked about the potential of MS to lower risk of death because of breast cancer, 215 (54.29\%) responded that it does not lower risk.

Univariate analysis indicated that participation in MS varied among age groups $(p=0.000 ;$ Table 2): Women aged 40 to 49 years participated 2.6 times less often every year $(\mathrm{OR}=0.380 ; 95 \% \mathrm{Cl}: 0.170-0.847)$, and 10.2 times less often every second year (OR $=0.098 ; 95 \% \mathrm{Cl}$ : 0.024- 0.402), compared with women aged $\geq 70$ years (Table 2). Women with low and middle educational level participated 8.1 times less often (OR $=0.123 ; 95 \% \mathrm{Cl}$ :0.330- 0.465) and 4.8 times less often $(\mathrm{OR}=0.207 ; 95 \% \mathrm{Cl}$ : 0.049-0.867), respectively, in biannual MS, compared to women with high educational level (Table 2). Furthermore, women with no family history of breast cancer had a 2.4 (OR = 0.424; 95\% Cl: 0.215-0.835) times reduced chance of participation in annual MS compared to women with family history (Table 2). Occupation status had borderline significance $(p=0.061)$, whereas heterogeneous data distribution of marital status, income and ethnic origin were insignificant (Table 2).

Women with low absolute perceived risk had a two-fold (OR $=0.493 ; 95 \% \mathrm{Cl}$ : 0.243- 1.000$)$ decreased chance of participating annually in an MS program (Table 3). If absolute perceived risk was compared with real risk, obtained from the Gail model of risk estimation, then accurate perception of risk and even its overestimation, were negatively correlated with participation in MS (Table 3): Values of accurate risk perception and overestimation of numeric and comparative perceived risk, respectively, indicated a negative correlation with participation in MS ( $p=$ $0.021 ; p=0.017 ;$ Table 3).

Among women aged 50 years and older, no age-dependent differences of MS performance were detected ( $p=$ 0.545). Because participation in MS among women aged 40 to 49 years and women aged $\geq 50$ showed remarkable differences (Table 2), data were stratified into two groups. Age-dependent stratification revealed that perceived absolute risk and family history had a stronger impact among women who were between 40 and 49 years old (Table 4). In this age group, regular participation in MS was about 2.7-fold decreased $(\mathrm{OR}=0.366$; 95\% Cl: $0.144-0.934)$ and 4.4-fold decreased (OR= 0.228; $95 \% \mathrm{Cl}: 0.088-0.587)$ for women with low absolute perceived risk and no family history, respectively, when compared to women with high perceived risk and positive family history (Table 4). For women aged $\geq 50$ years, by contrast, these effects were less prominent and were not significant ( $p=0.556 ; p=0.302$, Table 4). Perception of absolute risk was dependent on family history, and this effect was more prominent among women aged $\geq 50$ years (Table 4): Women aged 40 to 49 years and $\geq 50$ years with no family history, had a 5.777 (95\% Cl: 2.261- 14.764) and 9.239 (95\%Cl: 4.028- 21.194) higher chance, respectively, to have low absolute risk perception when compared to women with family history (Table 4).

Overestimation of numeric risk was associated with having no family history of breast cancer: Women without family history, aged 40 to 49 years and $\geq 50$ years, had a $3.13(\mathrm{OR}=0.320 ; 95 \% \mathrm{Cl}$ : $0.122-0.837 ; p=0.013)$ and $11.24(\mathrm{OR}=0.089 ; 95 \% \mathrm{Cl}: 0.012-0.674 ; \mathrm{p}=0.000)$ times lower chance, respectively, to overestimate numeric risk compared to women with family history. Furthermore, women aged $\geq 50$ years, who overestimated comparative 
risk, had an about $2.9(\mathrm{OR}=0.347 ; 95 \% \mathrm{Cl}$ : $0.107-1.130 ; \mathrm{p}=0.000)$ times lower chance to have no family history. In the case of women aged 40- 49 years, there was a borderline significant association between comparative risk and family history $(p=0.063)$. Women with accurate $(83.83 \%)$ comparative risk perception had a $3.639(95 \% \mathrm{Cl}$ : 0.972-13.626) times higher chance to have no family history, compared with women who underestimated comparative risk.

Regression modeling was performed to identify independent variables. Variables of univariate analysis with $p<$ 0.2 were used for modeling. Women aged 40 - 49 years with low perceived absolute risk underwent regular MS 2.7 $(\mathrm{OR}=0.377 ; 95 \% \mathrm{Cl}: 0.143-0.989)$ times less often than did women with high perception of absolute risk (Table 5). In this model, women with low educational level also underwent regular MS $2.7(\mathrm{OR}=0.368 ; 95 \% \mathrm{Cl}$ : 0.100-1.360) times less often than did women with high educational level (Table 5). In a second model, perceived absolute risk was substituted by family history of breast cancer $(p=0.002)$ : Women without family history underwent regular MS $4.2(\mathrm{OR}=0.241 ; 95 \% \mathrm{Cl}$ : 0.091-0.639) times less often than did women with family history. In the second model, education had borderline significance $(p=0.061)$. Women with low educational level underwent regular MS $2.9(\mathrm{OR}=0.351 ; 95 \% \mathrm{Cl}: 0.090-1.304)$ times less often than did women with high educational level. For women aged $\geq 50$ years by contrast, family history and perceived absolute risk were not associated with heterogeneous distribution of data $(p=0.302 ; p=0.407)$. Modeling revealed that, in this age group, education was the only variable that remained significant $(p=0.021)$. Compared to women with high educational level, those with low educational level underwent annual and biannual MS $3.5(\mathrm{OR}=0.289 ; 95 \% \mathrm{Cl}$ : $0.035-2.363)$ and $23.3(\mathrm{OR}=0.043$; 95\% Cl: 0.004-0.420) times less often, respectively.

\section{Discussion}

To the best of our knowledge, this is the first Brazilian study to analyze women's risk perception and its impact on MS behavior. Perception of low absolute risk was positively associated with non-participation in MS. Similarly a recent study associated perceived high absolute risk as a predictor of MS participation [24]. Our results suggested that most women had an accurate (80.05\%) estimation of comparative risk, and an overestimated (56.82\%) numeric risk. Accurate and overestimated perceived numeric and comparative risk all tended to be inversely associated with participation in MS. This was surprising, as most previous studies did not reveal any positive or negative association of numeric and comparative risk perception with participation in MS $[10,12,16,20]$. Labrie and colleagues [24] suggested that fear of breast cancer increased the perception of personal risk among women aged 30 - 49 years. A recent study performed in Malta suggested that non-adherence to organized MS programs was associated with fear [25]. Similarly, women in our present study who feared the disease might have tended to overestimate numeric risk, estimate comparative risk mainly accurate and fear could also lead to avoidance of MS. Notably, more than $90 \%$ of interviewed women knew that MS cannot prevent breast cancer, however more than a half of all 396 women denied that it can lower the risk of dying from breast cancer. This indicated that most women also did not consider MS to be beneficial. Furthermore, regular participation on MS could also lead to underestimation of risk.

Brazilian women aged 40 - 49 years are exposed to conflicting public recommendations regarding the benefit of MS. As the ministry of health recommends an age threshold of 50 years, it was not surprising that women aged 40 - 49 generally had a lower participation rates in MS, compared with those of older women. Interestingly, family history of breast cancer and educational level had different effects in both age groups. 
Our data suggest that women with lower educational levels tended to undergo MS less often. In recent studies from various countries, high educational level was one of the most important predictors of adherence to MS [2629]. In agreement with our results, several Brazilian studies reported a greater chance of adherence to MS among women with higher educational levels [5,8,30-32]. In a recent study also performed in the Northeast region of Brazil, educational level did not have a significant impact on regular participation; instead, high income was positively associated with MS participation [9]. This could mean that the impact of income and educational levels may vary within Brazil, depending on regional differences. The study of Freitas and colleagues [9] was performed in a smaller town where differences of income may be more prominent than educational differences. The nationwide adherence study by Narayan and colleagues (2017) in the US, identified both high income and educational level as important predictors of adherence to MS [27].

Family history was the second important variable in our study. Women without family history had a reduced chance of participation in regular MS. This result agrees with previous Brazilian studies that reported lower participation in MS among women without family history of cancer [9,30]. Similarly, studies from Iran and the US reported a positive association between family history of breast cancer and adherence to MS programs [18,20].

Our data suggest that, in both age groups, perception of absolute risk was dependent on family history of breast cancer: In women aged $\geq 50$ years this effect was more prominent than for women aged 40 - 49 years. In a Turkish study, perception of absolute risk did not depend on family history [14]. By contrast, similar to our results, other studies performed in Turkey, Canada and the US revealed a positive association between family history of breast cancer and numeric and comparative risk perception [12,18,33]. In the present study, during modeling of data, the family history and perception of absolute risk behaved exclusively and interchangeably for women aged 40 - 49 years. Furthermore, only among women aged 40 - 49 years, risk perception and education both contributed as independent variables to the regression model. In a second model, regular participation in MS was dependent on family history in women aged 40 - 49 years, whereas education had borderline significance. In the case of women aged $\geq 50$ years, by contrast, education was the only significant variable that determined prevention behavior. These results suggested that in women aged 40 - 49 years, risk perception and family history had a stronger influence on screening behavior than it did for women aged $\geq 50$ years. Due to the uncertainty of the possible benefit of MS, the decision of women aged 40 - 49 years to participate may be more strongly influenced by personal risk perception and family history.

Our study had several limitations: Participants were randomly selected. However, a selection bias that favors a certain socioeconomic background and a defined risk perception of breast cancer cannot be excluded. Perceived risk was determined as a categorical, rather than as a continuous variable. This may have obscured the power of the study to detect more detailed associations with MS behavior. Results of our study cannot necessarily be extrapolated to other regions of the country, particularly as income was an important variable in several previous Brazilian studies. For women aged $\geq 50$ years, only educational level was identified as a variable with heterogeneous distribution. Low resolution of data may have been linked to small sample size. Finally, the study did not elucidate why women with accurate perceived comparative risk and overestimation of numeric risk participated less often in MS, compared with women who underestimated risk.

\section{Conclusions}

Educational level and family history, in combination with perception of absolute risk, were the most important variables explaining heterogeneity of women's mammography screening behavior. Educational level and family 
history, combined with perception of absolute risk, were decisive variables for women aged 40 - 49 years. In the case of women aged $\geq 50$ years, both perception and family history played an insignificant role, whereas educational level was the only independent variable. Results suggest that public MS programs should have a focus on women with low educational levels. Future studies should elucidate why many women who overestimate risk, or who estimate it accurately, do not participate in MS. Fear could be an important psychological variable that determines both overestimation and avoidance behavior. It might be desirable for health authorities to provide more detail regarding the benefits and limits of MS. More than a half of women did not understand that MS is capable of reducing the risk of death from breast cancer. Conflicting opinions regarding its benefit are probably confusing women aged 40 - 49 years. Prospective Brazilian studies regarding the benefit of MS are lacking, and it is to date unclear whether MS can decrease mortality rate of breast cancer among women aged 40 - 49 years.

\section{Declarations}

MS: Mammography screening.

\section{Declarations}

\section{Ethical approval and consent to participate}

The data sampling protocol was reviewed and approved by the Brazilian National Ethics Research Committee (CAAE Plataforma Brasil: 63089416.0.0000.5187). Written informed consent was obtained from each participant of the study.

\section{Consent for publication}

Consent to publish data anonymously was obtained from each participant of the study.

\section{Availability of data}

The datasets used during the current study are available from the corresponding author on reasonable request.

\section{Competing interests}

The authors declare that they have no interests that compete with any of the contents of the manuscript.

\section{Funding}

This work was funded by the Brazilian "Coordenação de Aperfeiçoamento de Pessoal de Nível Superior (CAPES)". 
Authors' contributions

SAVA performed interviews and tabulation of data. MW performed study design and manuscript draft. Authors equally contributed to conception and critical review of the manuscript. Both authors read and approved the final manuscript.

\section{Acknowledgements}

We would like to thank all participating women of Campina Grande. We also would like to thank the staff of the health service center "Dr. Francisco Pinto" and the "Hospital Municipal Dr. Edgley.

\section{References}

1. Torre LA, Siegel RL, Ward EM, Jema A: Global Cancer Incidence and Mortality Rates and Trends-An Update. Cancer Epidemiol Biomarkers Prev 2016, 25(1):16-27. doi: 10.1158/1055-9965.EPI-15-0578.

2. Instituto Nacional do Câncer (INCA, 2016). Estimativa 2016: Incidencia de câncer no Brasil. [http://www.inca.gov.br/estimativa/2016/].

3. Instituto Nacional do Câncer (INCA, 2005). Estimativa 2005: Incidência de câncer no Brasil. [http://www1.inca.gov.br/vigilancia/docs/portugal2005/ estimativa\%202005.pdf].

4. Urban LABD, Schaefer MB, Duarte DL et al: Recomendações do Colégio Brasileiro de Radiologia e Diagnóstico por Imagem, da Sociedade Brasileira de Mastologia e da Federação Brasileira das Associações de Ginecologia e Obstetrícia para rastreamento do câncer de mama por métodos de imagem. Radiol Bras 2012, 45:6.

5. Silva TB, Mauad EC, Carvalho AL, Jacobs LA, Shulman LN: Difficulties in implementing an organized screening program for breast cancer in Brazil with emphasis on diagnostic methods. Rural and Remote Health 2013, 13:2321.

6. Schneider IJC, Corseuil MW, Boing AF, D'Orsi E: Knowledge about mammography and associated factors: population surveys with female adults and elderly. Rev Bras Epidemiol 2013,16(4):930-42.

7. Andrade ACM, Ferreira Júnior CA, Guimarães BD, et al: Molecular breast cancer subtypes and therapies in a public hospital of Northeastern Brazil. BMC Women's Health 2014, 14:110.

8. Vieira RAC, Lourenço TS, Mauad EC, et al: Barriers related to non-adherence in a mammography breastscreening program during the implementation period in the interior of São Paulo State, Brazil. $J$ Epidemiol Global Health 2015, 5:211-9.

9. Freitas AGQ and Weller M: Knowledge about Risk Factors of Breast Cancer and Its Effect on Women's Screening Behaviour in a Community of Rio Grande do Norte, North-eastern Brazil. Breast J 2017, 23(3):365-66. doi: 10.1111/tbj.12746. 
10. Graves KD, Huerta E, Cullen J, et al: Perceived risk of breast cancer among Latinas attending community clinics: risk comprehension and relationship with mammography adherence. Cancer Causes Contro/ 2008, 19(10):1373-82.

11. Banegas MP, Püschel K, Martinez J, Anderson JC, Thompson B: Perceived and objective breast cancer risk assessment in Chilean women living in an underserved area. Cancer Epidemiol Biomarkers Prev 2012, 21(10): 1716-21.

12. Walker MJ, Mirea L, Glendon G, Ritvo P, Andrulis IL, Knight JA, Chiarelli AM: Does perceived risk predict breast cancer screening use? Findings from a prospective cohort study of female relatives from the Ontario site of the Breast Cancer Family Registry. Breast 2014, 23(4):482-8.

13. Fehniger J, Livaudais-Toman J, Karliner L, et al: Perceived Versus Objective Breast Cancer Risk in Diverse Women. J Womens Health (Larchmt) 2014, 23(5):420-27.

14. Kartal M, Ozcakar N, Hatipoglu S et al: Breast cancer risk perceptions of Turkish women attending primary care: a cross-sectional study. BMC Women's Health 2014, 14:152

15. Evans DGR, Donnelly LS, Harkness EF, et al: Breast cancer risk feedback to women in the UK NHS breast screening population. Br J Cancer 2016, 26, 114(9):1045-52. doi: 10.1038/bjc.2016.56.

16. Ceber E , Soyer MT, Ciceklioglu M, Cimat S: Breast cancer risk assessment and risk perception on nurses and midwives in Bornova Health District in Turkey. Cancer Nurs 2006, 29(3):244-9.

17. Zhang LR, Chiarelli AM, Glendon G, et al: Influence of perceived breast cancer risk on screening behaviours of female relatives from the Ontario Site of the Breast Cancer Family Registry. Eur J Cancer Prev 2011, 20(4):255-62. doi:10.1097/CEJ.0b013e3283447467.

18. Haber G, Ahmed NU, Pekovic V: History of Cancer and Its Association With Breast Cancer Risk Perception and Repeat Mammography. Am J Public Health 2012, 102(12):2322-9. doi: 10.2105/AJPH.2012.300786.

19. Chung C, Lee SJ: Estimated risks and optimistic self-perception of breast cancer risk in Korean women. Appl Nurs Res 2013, 26(4):180-5. doi: 10.1016/j.apnr.2013.06.001.

20. Khoshravesh S, Taymoori P, Roshani D: Evaluation of the Relationship Between Family History of Breast Cancer and Risk Perception and Impacts on Repetition of Mammography. Asian Pac J Cancer Prev $2016,17$. Cancer Control in Western Asia. Special Issue, 135-141.

21. Brazilian institute of Geography and Statistics (IGBE, 2010). [http://cidades.ibge.gov.br/painel/ painel.php? codmun=250400].

22. Freitas AGQ and Weller M: Knowledge about Risk Factors for Breast Cancer and Having a Close Relative with Cancer Affect the Frequency of Breast Self-Examination Performance. Asian Pac J Cancer Prev 2016, 17(4):207581.

23. Gail MH, Brinton LA, Byar DP, et al: Projecting individualized probabilities of developing breast cancer for white females who are being examined annually. J Natl Cancer Inst 1989, 81:1879-86. 
24. Labrie NHM, Ludolph R, Schulz PJ: Investigating young women's motivations to engage in early mammography screening in Switzerland: results of a crosssectional study. BMC Cancer 2017, 17:209.

25. Marmarà D, Marmarà V, Hubbard G: Health beliefs, illness perceptions and determinants of breast screening uptake in Malta: a cross-sectional survey. BMC Public Health 2017, 17:416.

26. Elias N, Bou-Orm IR, Adib SM: Patterns and determinants of mammography screening in Lebanese women. Prev Med Rep 2016, 23(5):187-193. doi: 10.1016/j.pmedr.2016.12.015.

27. Narayan A, Fischer A, Zhang Z, et al: Nationwide cross-sectional adherence to mammography screening guidelines: national behavioural risk factor surveillance system survey results. Breast Cancer Res Treat 2017, 164(3):719-725. doi: 10.1007/s10549-017-4286-5.

28. Sandoval JL, Theler JM, Cullati S, et al: Introduction of an organised programme and social inequalities in mammography screening: A 22-year population-based study in Geneva, Switzerland. Prev Med 2017, 103:49-55. doi: 10.1016/j.ypmed.2017.07.025.

29. Gang M, Kim JI Oh KO, Li CY, Song Y: Factors associated with mammography adherence among married Chinese women in Yanbian, China. Asian Pac J Cancer Prev 2013, 14(12):7207-13.

30. Sclowitz ML, Menezes AMB, Gigante DP, Tessaro S: Condutas na prevenção secundária do câncer de mama e fatores associados. Rev Saúde Pública 2005, 39(3):340-49.

31. De Oliveira RD, Santos MC, Moreira CB, Fernandes AF: Detection of Breast Cancer: Knowledge, Attitude, and Practice of Family Health Strategy Women. J Cancer Educ 2017, 14. doi: 10.1007/s13187-017-1209-4.

32. Souza Cl, Araújo DS, Teles DA et al: Factors related to non-adherence to mammography in a city of the Brazilian Amazonian area: A population-based study. Rev Assoc Med Bras 2017, 63(1):35-42. doi: 10.1590/18069282.63.01.35.

33. Yüksel S, Altun Uğras G, Çavdar İ: A Risk Assessment Comparison of Breast Cancer and Factors Affected to Risk Perception of Women in Turkey: A Cross-sectional Study. Iran J Public Health 2017, 46(3):308-317.

\section{Tables}

Table 1. Socioeconomic variables distributed according to mammography participation $(\mathrm{N}=396)$. 


\begin{tabular}{|c|c|c|c|c|c|c|c|c|c|}
\hline & \multicolumn{2}{|c|}{$\begin{array}{c}\text { Never } \\
(\mathrm{N}=108)\end{array}$} & \multicolumn{2}{|c|}{$\begin{array}{l}\text { Sometimes } \\
\qquad(N=99)\end{array}$} & \multicolumn{2}{|c|}{$\begin{array}{l}\text { Each year } \\
(\mathrm{N}=168)\end{array}$} & \multicolumn{2}{|c|}{ Each second year } & $\mathbf{P}$ \\
\hline \multicolumn{10}{|l|}{ Age } \\
\hline Mean & (SL & $\begin{array}{l}4 \\
=12.10)\end{array}$ & 57. & $=11.90)$ & 55.5 & 10.74) & 60. & $=9.89)$ & 0.000 \\
\hline Years & $\mathbf{N}$ & $\%$ & $\mathbf{N}$ & $\%$ & $\mathbf{N}$ & $\%$ & 1 & $\%$ & \\
\hline 40- 49 & 75 & $69.44 \%$ & 31 & $31.31 \%$ & 57 & $33.93 \%$ & 4 & $19.05 \%$ & 0.000 \\
\hline 50- 59 & 13 & $12.04 \%$ & 32 & $32.32 \%$ & 51 & $30.36 \%$ & 6 & $28.57 \%$ & \\
\hline $60-69$ & 9 & $8.33 \%$ & 17 & $17.17 \%$ & 38 & $22.62 \%$ & 5 & $23.81 \%$ & \\
\hline$\geq 70$ & 11 & $10.19 \%$ & 19 & $19.20 \%$ & 22 & $13.09 \%$ & 6 & $28.57 \%$ & \\
\hline \multicolumn{10}{|l|}{ Education } \\
\hline Low & 73 & $67.59 \%$ & 70 & $70.71 \%$ & 98 & $58.34 \%$ & 9 & $42.86 \%$ & 0.005 \\
\hline Middle & 29 & $26.85 \%$ & 25 & $25.25 \%$ & 54 & $32.14 \%$ & 6 & $28.57 \%$ & \\
\hline High & 6 & $5.56 \%$ & 4 & $4.04 \%$ & 16 & $9.52 \%$ & 6 & $28.57 \%$ & \\
\hline \multicolumn{10}{|c|}{ Marital status } \\
\hline No union & 40 & $62.96 \%$ & 37 & $37.37 \%$ & 67 & $39.88 \%$ & 8 & $38.10 \%$ & 0.963 \\
\hline Union & 68 & $37.04 \%$ & 62 & $62.63 \%$ & 101 & $60.12 \%$ & 13 & $61.90 \%$ & \\
\hline \multicolumn{10}{|c|}{ Ethnic origin } \\
\hline Caucasian & 72 & $66.67 \%$ & 65 & $65.66 \%$ & 106 & $63.10 \%$ & 13 & $61.90 \%$ & 0.923 \\
\hline Other one & 36 & $33.33 \%$ & 34 & $34.34 \%$ & 62 & $36.90 \%$ & 8 & $38.10 \%$ & \\
\hline \multicolumn{10}{|l|}{ Income } \\
\hline Low & 75 & $69.44 \%$ & 62 & $62.63 \%$ & 103 & $61.31 \%$ & 9 & $42.86 \%$ & 0.373 \\
\hline Middle & 30 & $27.78 \%$ & 33 & $33.33 \%$ & 57 & $33.93 \%$ & 10 & $47.62 \%$ & \\
\hline High & 3 & $2.78 \%$ & 4 & $4.04 \%$ & 8 & $4.76 \%$ & 2 & $9.52 \%$ & \\
\hline \multicolumn{10}{|c|}{ Occupation status } \\
\hline Occupied & 31 & $28.70 \%$ & 35 & $52.70 \%$ & 36 & $21.43 \%$ & 8 & $38.10 \%$ & 0.061 \\
\hline Not occup. & 77 & $71.30 \%$ & 34 & $47.30 \%$ & 132 & $78.57 \%$ & 13 & $61.90 \%$ & \\
\hline \multicolumn{10}{|c|}{ Family history of breast cancer } \\
\hline No & 95 & $87.96 \%$ & 89 & $89.90 \%$ & 127 & $75.60 \%$ & 17 & $80.95 \%$ & 0.008 \\
\hline Yes & 13 & $12.04 \%$ & 10 & $10.10 \%$ & 41 & $24.40 \%$ & 4 & $19.05 \%$ & \\
\hline
\end{tabular}


$\mathrm{SD}=$ Standard deviation

Table 2. Odds ratio (OR) and confidence intervals (CI) are presented for single socio-economic variables. 


\begin{tabular}{|c|c|c|c|c|c|}
\hline & & $\begin{array}{l}\text { Sometimes } \\
\qquad(\mathrm{N}=99)\end{array}$ & $\begin{array}{l}\text { Each year } \\
(\mathrm{N}=168)\end{array}$ & $\begin{array}{l}\text { Each second year } \\
\qquad(\mathrm{N}=21)\end{array}$ & $\mathbf{P}$ \\
\hline & N (\%) & $\mathrm{OD}(\mathrm{CI})$ & $\mathrm{OD}(\mathrm{CI})$ & $\mathrm{OD}(\mathrm{CI})$ & \\
\hline \multicolumn{6}{|l|}{ Age } \\
\hline 40- 49 years & 167 (42.17) & $\begin{array}{c}0.239 * \\
(0.102-0.561)\end{array}$ & $\begin{array}{c}0.380 * \\
(0.170-0.847)\end{array}$ & $\begin{array}{c}\text { 0.098* } \\
(0.024-0.402)\end{array}$ & \multirow[t]{4}{*}{0.000} \\
\hline 50- 59 years & $102(25.76)$ & $\begin{array}{c}1.43 \\
(0.533-3.810)\end{array}$ & $\begin{array}{c}1.962 \\
(0.762-5.051)\end{array}$ & $\begin{array}{c}0.846 \\
(0.211-3.389)\end{array}$ & \\
\hline 60- 69 years & $69(17.42)$ & $\begin{array}{c}1.094 \\
(0.365-3.277)\end{array}$ & $\begin{array}{c}2.111 \\
(0.757-5.887)\end{array}$ & $\begin{array}{c}1.019 \\
(0.232-4.466)\end{array}$ & \\
\hline$\geq 70$ years & $58(14.65)$ & \multicolumn{3}{|c|}{ Ref. } & \\
\hline \multicolumn{6}{|l|}{ Education } \\
\hline Low & 250 (63.13\%) & $\begin{array}{c}1.438 \\
(0.389-5.315)\end{array}$ & $\begin{array}{c}0.503 \\
(0.188-1.349)\end{array}$ & $\begin{array}{c}0.123^{*} \\
(0.330-0.465)\end{array}$ & \multirow[t]{3}{*}{0.021} \\
\hline Middle & 114 (28.79\%) & $\begin{array}{c}1.293 \\
(0.327-5.107)\end{array}$ & $\begin{array}{c}0.698 \\
(0.247-1.978)\end{array}$ & $\begin{array}{c}0.207^{*} \\
(0.049-0.867)\end{array}$ & \\
\hline High & 32 (8.08\%) & \multicolumn{3}{|c|}{ Ref. } & \\
\hline \multicolumn{6}{|l|}{ Marital status } \\
\hline No union & 152 (38.38\%) & $\begin{array}{c}1.015 \\
(0.577-1.784)\end{array}$ & $\begin{array}{c}1.128 \\
(0.685-1.855)\end{array}$ & $\begin{array}{c}1.046 \\
(0.399-2.742)\end{array}$ & \multirow[t]{2}{*}{0.963} \\
\hline Stable union & $244(61.62 \%)$ & \multicolumn{3}{|c|}{ Ref. } & \\
\hline \multicolumn{6}{|l|}{ Ethnic origin } \\
\hline Caucasian & $140(35.35 \%)$ & $\begin{array}{c}1.046 \\
(0.588-1.862)\end{array}$ & $\begin{array}{c}1.170 \\
(0.704-1.945)\end{array}$ & $\begin{array}{c}1.231 \\
(0.468-3.238)\end{array}$ & \multirow[t]{2}{*}{0.923} \\
\hline Mixed ethnicity & 256 (64.65\%) & \multicolumn{3}{|c|}{ Ref. } & \\
\hline \multicolumn{6}{|l|}{ Income } \\
\hline Low & 249 (62.88\%) & 0.620 & 0.515 & 0.713 & 0.399 \\
\hline
\end{tabular}




\begin{tabular}{|l|c|c|c|c|} 
& & $(0.134-2.876)$ & $(0.132-2.006)$ & $(0.176-2.885)$ \\
\hline Middle & $130(32.83 \%)$ & 0.825 & 0.180 & 0.500 \\
& & $(0.171-3.991)$ & $(0.026-1.225)$ & $(0.073-3.435)$ \\
\hline High & $17(4.29 \%)$ & \multicolumn{3}{|c|}{ Ref. } \\
\hline
\end{tabular}

\section{Occupation status}

\begin{tabular}{|c|c|c|c|c|c|}
\hline Occupied & 110 (27.78\%) & $\begin{array}{c}0.736 \\
(0.410-1.323)\end{array}$ & $\begin{array}{c}1.476 \\
(0.846-2.575)\end{array}$ & $\begin{array}{c}0.654 \\
(0.247-1.733)\end{array}$ & 0.062 \\
\hline Not occupied & 286 (72.22\%) & & Ref. & & \\
\hline
\end{tabular}

Family history of breast cancer

\begin{tabular}{|l|c|c|c|c|c|}
\hline No & $328(82.83 \%)$ & 1.218 & $0.424^{*}$ & 0.582 & 0.008 \\
& & $(0.508-2.918)$ & $(0.215-0.835)$ & $(0.169-1.997)$ & \\
\cline { 1 - 5 } Yes & $68(17.17 \%)$ & \multicolumn{3}{|c|}{ Ref. } & \\
\hline
\end{tabular}

$* \mathrm{P} \leq 0.05$

Women who did not participate in MS $(\mathrm{N}=108)$ served as reference group.

Table 3. Risk perception compared to real risk of women $(\mathrm{N}=396)$ and adherence to a MS program. 


\begin{tabular}{|c|c|c|c|c|c|c|}
\hline & \multicolumn{3}{|c|}{ Mammography screening } & \multirow[b]{2}{*}{$\mathbf{P}$} \\
\hline & & & \multirow{2}{*}{$\begin{array}{l}\text { Sometimes } \\
\qquad(\mathrm{N}=99) \\
\text { OD }(95 \% \mathrm{CI})\end{array}$} & \multirow{2}{*}{$\begin{array}{l}\text { Each year } \\
(\mathrm{N}=168) \\
\text { OD }(95 \% \mathrm{CI})\end{array}$} & \multirow{2}{*}{$\begin{array}{l}\text { Each second year } \\
\qquad(\mathrm{N}=21) \\
\text { OD }(95 \% \mathrm{CI})\end{array}$} & \\
\hline & & N (\%) & & & & \\
\hline \multicolumn{7}{|c|}{ Absolute perceived risk } \\
\hline \multicolumn{2}{|c|}{ Low } & 340 (85.86\%) & $\begin{array}{c}1.250 \\
(0.503-3.108)\end{array}$ & $\begin{array}{c}0.493^{*} \\
(0.243-1.000)\end{array}$ & $\begin{array}{c}2.500 \\
(0.307-20.336)\end{array}$ & \multirow[t]{2}{*}{0.020} \\
\hline \multicolumn{2}{|c|}{ High } & $56(14.14 \%)$ & \multicolumn{3}{|c|}{ Ref. } & \\
\hline \multicolumn{7}{|c|}{ Numeric perceived risk } \\
\hline \multicolumn{2}{|c|}{ Overestimation } & 225 (56.82\%) & $\begin{array}{c}0.216^{*} \\
(0.056-0.827)\end{array}$ & $\begin{array}{c}0.352 \\
(0.097-1.271)\end{array}$ & $\begin{array}{c}0.117^{*} \\
(0.023-0.603)\end{array}$ & \multirow[t]{3}{*}{0.021} \\
\hline \multicolumn{2}{|c|}{ Accurate } & 140 (35.35\%) & $\begin{array}{c}0.315 \\
(0.081-1.225)\end{array}$ & $\begin{array}{c}0.256^{*} \\
(0.069-0.953)\end{array}$ & $\begin{array}{c}0.128 * \\
(0.023-0.700)\end{array}$ & \\
\hline \multicolumn{2}{|c|}{ Underestimation } & $\begin{array}{c}31 \\
(7.83 \%)\end{array}$ & \multicolumn{3}{|c|}{ Ref. } & \\
\hline \multicolumn{7}{|c|}{ Comparative perceived risk } \\
\hline \multicolumn{2}{|c|}{ Overestimation } & $\begin{array}{c}39 \\
(9.85 \%)\end{array}$ & $\begin{array}{c}0.444 \\
(0.096-2.057)\end{array}$ & $\begin{array}{c}0.406 \\
(0.109-1.516)\end{array}$ & $\begin{array}{c}0.089 \\
(0.080-1.029)\end{array}$ & 0.017 \\
\hline \multicolumn{2}{|c|}{ Accurate } & 317 (80.05\%) & $\begin{array}{c}0.437 \\
(0.127-1.503)\end{array}$ & $\begin{array}{c}0.227^{*} \\
(0.076-0.678)\end{array}$ & $\begin{array}{c}0.126^{*} \\
(0.030-0.524)\end{array}$ & \\
\hline \multicolumn{2}{|c|}{ Underestimation } & $\begin{array}{c}40 \\
(10.10 \%)\end{array}$ & \multicolumn{3}{|c|}{ Ref. } & \\
\hline \multicolumn{7}{|c|}{ Family history } \\
\hline & & & \multicolumn{3}{|c|}{ Low absolute perceived risk } & \\
\hline No & \multicolumn{2}{|c|}{328 (82.83\%) } & \multicolumn{3}{|c|}{$7.500(4.038-13.929)$} & \multirow[t]{2}{*}{0.000} \\
\hline Yes & $68(17$ & $17 \%)$ & & Ref. & & \\
\hline
\end{tabular}


$* \mathrm{P} \leq 0.05$

Data of women who underwent mammography $(\mathrm{N}=288)$ compared to those who never underwent mammogra] 108) are presented as odds ratios (OR) and confidence intervals (CI). Perception of absolute risk was dependent history of breast cancer. OR and CI for low absolute risk perception are shown for women with family history, con those ones without it.

Table 4. MS and age dependent effect of perceived absolute risk, respectively, family history. 


\begin{tabular}{|c|c|c|c|c|c|c|c|}
\hline \multicolumn{8}{|c|}{ Mammography screening } \\
\hline & \multicolumn{2}{|c|}{ Never } & \multicolumn{2}{|c|}{ Sometimes } & \multicolumn{2}{|c|}{ Each year or second year } & \multirow[t]{2}{*}{$\mathbf{P}$} \\
\hline & \multicolumn{2}{|l|}{$\mathbf{N}$} & $\mathbf{N}$ & $\%$ & $\mathbf{N}$ & $\%$ & \\
\hline \multicolumn{8}{|l|}{ Age group } \\
\hline 40- 49 years & \multicolumn{2}{|r|}{$69.44 \%$} & 31 & $31.31 \%$ & 61 & $32.28 \%$ & \multirow[t]{2}{*}{0.000} \\
\hline$\geq 50$ years & 33 & $30.56 \%$ & 68 & $68.69 \%$ & 128 & $67.72 \%$ & \\
\hline & & N (\%) & \multicolumn{2}{|c|}{ OD $(95 \% \mathrm{CI})$} & \multicolumn{2}{|c|}{ OD (95\%CI) } & \\
\hline & \multicolumn{7}{|c|}{ Perceived absolute risk } \\
\hline 40- 49 years & Low & $142(85.03 \%)$ & $(0.3$ & $\begin{array}{l}1.731 \\
6-8.658)\end{array}$ & & $\begin{array}{l}\text { 6* } \\
\text { 0.934) }\end{array}$ & 0.027 \\
\hline \multirow[t]{3}{*}{$\geq 50$ years } & Low & $198(86.46 \%)$ & $(0.3$ & $\begin{array}{l}1.202 \\
6-4.435)\end{array}$ & & $\begin{array}{l}45 \\
2.350)\end{array}$ & 0.556 \\
\hline & High & & & & Ref. & & \\
\hline & \multicolumn{6}{|c|}{ Family history of breast cancer } & \\
\hline 40- 49 years & No & $142(85.03 \%)$ & $(0.2$ & $\begin{array}{l}1.493 \\
2-7.622)\end{array}$ & & $\begin{array}{l}\text { 8* } \\
0.587)\end{array}$ & 0.000 \\
\hline \multirow[t]{2}{*}{$\geq 50$ years } & No & $189(82.53 \%)$ & $(0.5$ & $\begin{array}{l}1.667 \\
7-5.273)\end{array}$ & & $\begin{array}{l}72 \\
\text { 2.332) }\end{array}$ & 0.302 \\
\hline & Yes & & & & Ref. & & \\
\hline \multicolumn{8}{|c|}{ Low perceived absolute risk } \\
\hline & \multicolumn{6}{|c|}{ Family history of breast cancer } & \\
\hline 40- 49 years & No & $142(85.03 \%)$ & & & $\begin{array}{r}5.777^{*} \\
.261-14 .\end{array}$ & & 0.000 \\
\hline$\geq 50$ years & No & $189(82.53 \%)$ & & & $\begin{array}{r}9.239 * \\
.028-21 .\end{array}$ & & 0.000 \\
\hline & Yes & & & & Ref. & & \\
\hline
\end{tabular}


Odds ratios (OR) and confidence intervals (CI) are shown for women aged $40-49$ years $(\mathrm{N}=167)$ and $\geq 50$ ye 229), respectively. In both age groups perception of low absolute risk was dependent on breast cancer family Mammography never undertaken, and perception of high absolute risk, served as reference groups.

Table 5. Model of nominal logistic regression, representing women aged 40 - 49 years $(\mathrm{N}=167)$.

\begin{tabular}{|c|c|c|c|c|}
\hline & & \multicolumn{2}{|c|}{ Mammography screening } & \multirow[b]{2}{*}{$\mathbf{P}$} \\
\hline & & $\begin{array}{l}\text { Sometimes } \\
\qquad(\mathrm{N}=31)\end{array}$ & $\begin{array}{l}\text { Each year or each second year } \\
\qquad(N=61)\end{array}$ & \\
\hline & N (\%) & OD $(95 \% C I)$ & OD $(95 \% C I)$ & \\
\hline \multicolumn{5}{|c|}{ Education } \\
\hline Low & $87(52.10 \%)$ & $\begin{array}{c}2.116 \\
(0.231-19.365)\end{array}$ & $\begin{array}{c}0.368 \\
(0.100-1.360)\end{array}$ & 0.040 \\
\hline Middle & $68(40.72 \%)$ & $\begin{array}{c}2.374 \\
(0.246-22.858)\end{array}$ & $\begin{array}{c}1.025 \\
(0.276-3.813)\end{array}$ & \\
\hline High & $12(7.18 \%)$ & & Ref. & \\
\hline \multicolumn{5}{|c|}{ Perceived absolute risk } \\
\hline Low & 139 (83.23\%) & $\begin{array}{c}1.782 \\
(0.356-8.930)\end{array}$ & $\begin{array}{c}0.377^{*} \\
(0.143-0.989)\end{array}$ & 0.037 \\
\hline High & $28(16.77 \%)$ & & Ref. & \\
\hline
\end{tabular}

$* \mathrm{p}<0.05$

Odds ratios (OR) and confidence intervals (CI) are presented for women who underwent mammography $(\mathrm{N}=92)$, c with women who did not $(\mathrm{N}=75)$. 